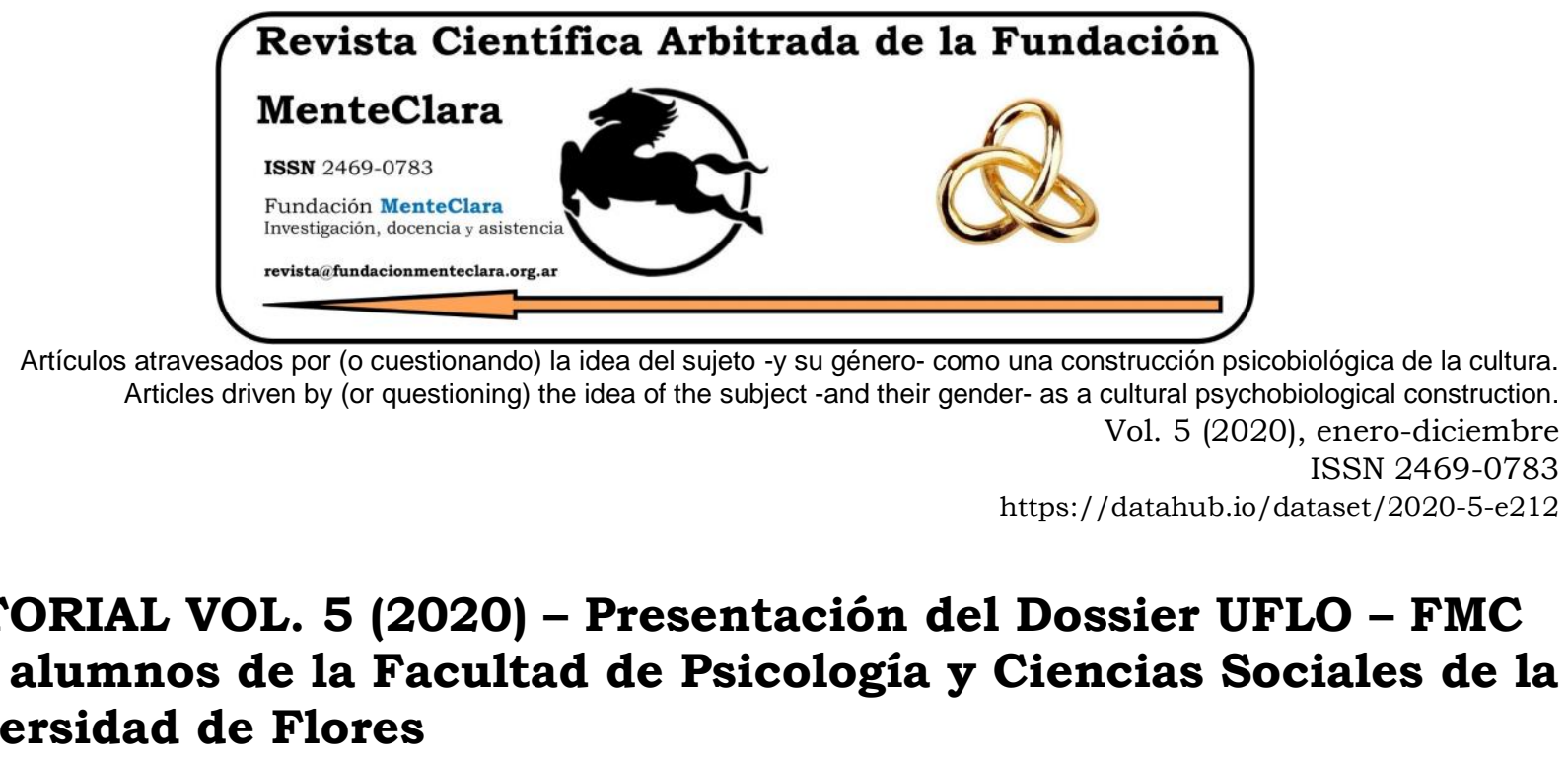

\title{
EDITORIAL VOL. 5 (2020) - Presentación del Dossier UFLO - FMC para alumnos de la Facultad de Psicologia y Ciencias Sociales de la Universidad de Flores
}

Autor: Paola Prozzillo, Universidad de Flores, Argentina. paola.prozzillo@uflo.edu.ar Editora responsable de este dossier

DOI: https://doi.org/10.32351/rca.v5.212

El presente dossier se gesta a partir de la propuesta lanzada por Fundación MenteClara internacional y la Cátedra Psicologia de la Salud de la Facultad de Psicología y Ciencias Sociales de la Universidad de Flores, quienes han convocado a la participación de los estudiantes de la asignatura a la producción de artículos de revisión bibliográfica que contemplen en su desarrollo los constructos teóricos de incumbencia para la Psicología Positiva.

\section{Tema del dossier: Psicologia positiva}

En las últimas décadas del siglo XX la Psicología de la Salud comienza a posicionarse como un paradigma del saber psicológico que reformula el campo de estudio. Se produce, entonces un deslizamiento desde un centro gravitatorio que puso el acento -durante su desarrollo en el siglo XIX y XX- en la patología y en el conflicto, hacia otro que hace referencia a las fortalezas, virtudes, recursos cognitivos, emocionales, vinculares y macrosociales de los seres humanos. Esperamos que los artículos que integren el número monográfico contribuyan a sistematizar los hallazgos en este campo del conocimiento. 
El primer artículo "Una revisión general sobre la creatividad”, (Ricci, 2020), explora las distintas acepciones que ha tomado la creatividad, concluyendo que su desarrollo constituye un factor fundamental en el desarrollo personal y social del ser humano.

A continuación, "Influencia de la motivación en la actividad física, el deporte y la salud", (Pereyra, 2020), expone el valor de la motivación en el ámbito de la actividad física, el deporte y la salud.

En tercer lugar, el artículo "La inteligencia emocional y su relación con el apoyo social y el autoconcepto como factores que influyen en el rendimiento académico de estudiantes de los niveles primario, secundario y superior", (Medina, 2020), explora en qué medida la inteligencia emocional, el apoyo social y el autoconcepto influyen en el desempeño académico de estudiantes que transitan distintos niveles del sistema educativo.

En cuarto orden, el artículo "Estrategias de afrontamiento y su rol intermediario frente al estrés familiar. Revisión bibliográfica”, (Balboa, 2020), presenta la relación entre estrategias de afrontamiento, eventos estresores y bienestar en un sistema familiar.

Finalmente, el artículo "El optimismo y su relación con el bienestar psicológico", (Ferrer, 2020), indaga la relación entre estas variables, concluyendo en que el optimismo constituye un factor predictor del bienestar psicológico.

Los artículos incluidos en la publicación de este dossier forman parte de la experiencia de formación académica de estudiantes que se encuentran dando sus primeros pasos en el terreno de la investigación, avanzando en la construcción del conocimiento científico. 


\section{Referencias}

de Reyes Balboa, M. (2020). Estrategias de afrontamiento y su rol intermediario frente al estrés familiar. Revisión bibliográfica. Revista Científica Arbitrada de la Fundación MenteClara, Vol.5 (202). DOI: https://doi.org/10.32351/rca.v5.202

Ferrer C. (2020). El optimismo y su relación con el bienestar psicológico. Revista Científica Arbitrada de la Fundación MenteClara, Vol.5 (199). DOI: https://doi.org/10.32351/rca.v5.199

Medina, P. (2020). La inteligencia emocional y su relación con el apoyo social y el autoconcepto como factores que influyen en el rendimiento académico de estudiantes de los niveles primario, secundario y superior. Revista Científica Arbitrada de la Fundación MenteClara, Vol.5 (203). DOI: https://doi.org/10.32351/rca.v5.203

Pereyra, E. (2020). Influencia de la motivación en la actividad física, el deporte y la salud. Revista Científica Arbitrada de la Fundación MenteClara, Vol.5 (200). DOI: https://doi.org/10.32351/rca.v5.200

Ricci, P. (2020). Una revisión general sobre la creatividad. Revista Científica Arbitrada de la Fundación MenteClara, Vol.5 (201). DOI: https://doi.org/10.32351/rca.v5.201 